\title{
Pobreza, Injustiça, e Desigualdade Social: repensando a formação de Profissionais de Saúde
}

PALAVRAS-CHAVE:

- Educação;

- Saúde;

- Pobreza;

- Justiça Social.

KEY-WORDS:

- Education;

- Health;

- Poverty;

- Social Justice.

Recebido em: / /

Aprovado em: 04/11/2007

278 REVISTA BRASILEIRA DE EDUCAÇ̃̃o MÉDICA

\section{Poverty, Injustice and Social Inequality: rethinking the Health Professionals Formation}

Rosângela Minardi Mitre Cotta ${ }^{1}$ Andréia Patrícia Gomes ${ }^{2}$ Társis de Mattos Maia ${ }^{1}$ Kelly Alves Magalhães ${ }^{1}$ Emanuele Souza Marques ${ }^{1}$ Rodrigo Siqueira-Batista ${ }^{3}$

\section{R E S U M O}

A formação de profissionais de saúde, capazes de responder às demandas da coletividade, tem sido motivo de intensos debates, especialmente nas duas últimas décadas. Uma das questões centrais, neste contexto, é a crescente demanda por recursos humanos habilitados a atuar em situações onde a pobreza e a desigualdade são fatores determinantes e/ou agravantes dos processos de adoecimento. Com efeito, discutir a necessidade de mudanças na formação laboral em saúde, à luz dos princípios do Sistema Único de Saúde (SUS), é o objetivo do presente artigo.

\begin{abstract}
The health workers education, capable of answer the demands of the community, has been very discussed, specially in the two last decades. One of the central questions is the need of form human resources, becoming them apt it act in situations of the poverty and of the inequality. To discuss such aspects - in the scope of the Brazilian Health System - is the goal of the present article.
\end{abstract}

1 Universidade Federal de Viçosa, Minas Gerais, Brasil

2 Centro Universitário Serra dos Órgãos, Rio de Janeiro, Brasil.

${ }^{3}$ Centro Universitário Serra dos Órgãos, Rio de Janeiro, Brasil; Centro Federal de Educação Tecnológica de Química de Nilópolis, Rio de Janeiro, Brasil. 


\section{INTRODUÇÃO}

"A desconsideração total pela formação integral do ser humano e sua redução a puro treino fortalecem a maneira autoritária de falar de cima para baixo."

Paulo Freire

A educação ocupa posição de destaque nos processos de desenvolvimento e construção da sociedade. De fato, sua função se compõe em duas vertentes principais: (1) instruir profissionais, tornando-os qualificados e capazes de atender às demandas $\mathrm{e}$ às necessidades da sociedade, e, principalmente, (2) formar cidadãos comprometidos com a relevância, a efetividade, e a qualidade do seu trabalho ${ }^{1-3} \mathrm{e}$ capazes de refletir sobre sua própria inscrição no mundo ${ }^{4,5}$.

No tocante a educação laboral em saúde, alguns questionamentos podem ser feitos: Qual o perfil dos trabalhadores em saúde formados pelas instituições educacionais? A educação destes profissionais está embasada em qual conceito de saúde, em qual paradigma sanitário? Estarão eles preparados para trabalhar no sistema público de saúde - ou seja, aptos para desempenhar suas funções no âmbito do Sistema Único de Saúde (SUS) — ou na iniciativa privada? Terão se tornado hábeis, nos anos de formação, para lidar com a realidade de pobreza e de desigualdade, às quais está submetida a maior parte da população brasileira? Serão capazes de articular, complexa e adequadamente, a teoria e a prática? Estarão instrumentalizados para exercer sua atividade profissional de modo autônomo e justo, trabalhando, também, em prol do fortalecimento da autonomia da população atendida, de maneira a formar lídimos sujeitos?6,7 Estas e outras interrogações tem sido objeto de discussão, nas últimas décadas, por parte dos diferentes atores envolvidos na educação em saúde, tais como, categorias profissionais, instituições de formação, pesquisa e de serviço, além dos Ministérios da Educação e da Saúde, principalmente após a institucionalização do SUS',6-9.

O SUS foi concebido em um contexto desfavorável de crises ficais e reformas econômicas, de expansão e consolidação do setor privado, em um contexto social historicamente desigual ${ }^{10}$. Assim, apesar da instituição legal de um sistema único, público, universal e gratuito, o contexto estrutural desfavorável marcado pelas desigualdades sociais, além das restrições orçamentárias para a expansão do novo sistema de saúde, resultaram na migração de grupos sociais, especialmente as categorias profissionais mais organizadas e os setores mais bem remunerados da sociedade, para o sistema privado. ${ }^{10,11}$ Tal situação é conseqüência — aliado a outros aspectos — da difícil síntese entre universalidade e eqüidade, problema que tem perpassado todo processo de construção/ implantação do SUS.

Estes elementos têm nítida implicação no ensino superior em saúde, o qual se encontra em um momento de importantes (re)definições, uma vez que o mercado de trabalho e o SUS discutem uma urgente mudança no enfoque até então dado à formação dos seus profissionais, historicamente centrada em conceitos cientificistas - tais como atenção médicomedicamentosa e hospitalocêntrica, tecnificação do ato médico, especialização, cura e atendimento individualizado — os quais foram se constituindo a partir de uma leitura superficial e incompleta do Relatório Flexner ${ }^{8,12-14}$.

Considerando que, do total de serviços de saúde oferecidos, a maioria corresponde a serviços públicos, operacionalizados nos moldes do SUS, constata-se que a educação nesta área focada nos parâmetros contidos no relatório de Flexner não condiz com os princípios e as diretrizes do sistema - construído a partir do conceito amplo de saúde e do Paradigma de Produção Social da Saúde $8,12,15$ - o que leva a uma profunda distorção da educação, formatando profissionais alheios ao sistema de saúde vigente ${ }^{8,16,17}$.

Acrescente-se a isto a desarticulação, no Brasil, entre as políticas de educação e de saúde - na verdade, há ainda tímidas interseções entre estes campos - ocasionando espaços de produção de conhecimento baseados exclusivamente em referenciais teóricos e não em experiências práticas necessárias para o desenvolvimento humano e profissional, levando a uma dificuldade de transposição, pelo trabalhador, dos conhecimentos adquiridos na sua vida acadêmica para as ações cotidianas, acarretando uma dicotomia entre teoria e prática - entre o ideal e a realidade - na qual se pretende intervir $2,8,15,18,19$.

Tal realidade, marcada pelas crescentes desigualdades sociais e matizadas pela pobreza, configura-se em obstáculo ao desenvolvimento humano. Este, embora não seja um tema recente, tem sido amplamente discutido por meio dos Relatórios de Desenvolvimento Humano, os quais têm abordado, todos os anos, questões polêmicas como crise mundial da água20; democracia21; direitos humanos ${ }^{22}$; globalização ${ }^{23}$; racismo, violência ${ }^{24}$; liberdade cultural $^{25}$; e erradicação da pobreza ${ }^{26}$, dentre outros. Frente à necessidade de iniciativas mais eficazes para a promoção do desenvolvimento humano, foi acordado, entre 191 estadosmembros da Organização das Nações Unidas (ONU), em setembro de 2000, um conjunto de princípios relacionados ao desenvolvimento econômico, aos direitos humanos e à 
sustentabilidade ambiental, resumidos em oito objetivos para o ano de 2015, sendo o primeiro deles "erradicar a extrema pobreza e a fome", dando origem à Declaração do Milênio ${ }^{27,28}$.

No Brasil, tal discussão se aprofundou no $11^{\circ}$ Congresso Mundial de Saúde Pública e $8^{\circ}$ Congresso Brasileiro de Saúde Coletiva, realizados no Rio de Janeiro em agosto de 2006 cujo tema central foi "Saúde Coletiva no mundo globalizado: rompendo barreiras sociais, econômicas e políticas" originando a Declaração do $\mathrm{Rio}^{29}$. Neste documento concluiuse que a globalização acabou produzindo um "ciclo vicioso", com aumento das desigualdades que levam à pobreza e à exclusão social, com impacto negativo sobre as condições de vida e saúde - perspectiva mais amplamente discutida - e, por sua vez, agudizando ainda mais as iniqüidades sociais no país e entre nações, colocando em risco o cumprimento das metas de Desenvolvimento do Milênio.

Um outro momento importante foi a criação, em março de 2006, da Comissão Nacional sobre Determinantes Sociais em Saúde (CNDSS) ${ }^{30}$, sendo o Brasil, um dos primeiros países com esta iniciativa, com o apoio e incentivo da Organização Mundial da Saúde (OMS). Questões referentes à relação da pobreza com a violência, agravos à saúde, discriminação étnica, acesso precário aos serviços de saúde e educação, vícios, meio ambiente, medicamentos, desgaste do capital social (marcado pela corrosão nas relações de solidariedade), tem sido discutidas - tendo em vista suas respectivas participações, como determinantes, no complexo processo saúde-doença entrelaçada aos princípios norteadores do SUS27.

Considerando-se que as desigualdades sociais e a pobreza são fenômenos multidimensionais e dinâmicos, e que não se restringem aos aspectos socioeconômicos com os quais são normalmente identificados ${ }^{24,31-36}$, os profissionais de saúde devem estar atentos à forma como estes âmbitos podem interferir na saúde dos indivíduos e das populações. Com efeito, aliar as competências dos trabalhadores de saúde com as necessidades das diversas coletividades é primordial para educação bem sucedida no campo da saúde. Neste sentido, o objetivo do presente artigo é discutir a formação de profissionais de saúde frente ao contexto de crescentes desigualdades sociais, contribuindo, assim, para os debates em torno da necessidade de implementação e ativação de mudanças na formação em saúde.

\section{A SAÚDE NO CONTEXTO DAS DESIGUALDADES SOCIAIS E DA POBREZA}

O estado de saúde dos indivíduos resulta das trajetórias de desenvolvimento pessoal ao longo do tempo, conformadas pela biografia de cada um referida ao contexto social, econômico, político e tecnológico das sociedades nas quais tais trajetórias se desenvolveram. Assim, os mesmos processos que determinaram a estrutura da sociedade são os que geram as desigualdades sociais e produzem os perfis epidemiológicos de saúde e doença, tendo em vista que a saúde pode ser considerada como um fenômeno produzido socialmente e que algumas formas de organização social são mais sadias do que outras ${ }^{37}$.

Destarte, faz-se necessário conhecer o contexto em que se pretende intervir. O Brasil é a $13^{\mathrm{a}}$ economia do mundo. Todavia, seu Índice de Desenvolvimento Humano (IDH) é 0,792, colocando-o em 69º posição entre 177 países, além de ser o oitavo com pior distribuição de renda ${ }^{20,24}$. Ainda que tenha havido um declínio acentuado da desigualdade de renda entre 2001 e 2005 - medido pela queda do Coeficiente de Gini de $5 \%$ neste período (de 59,3 para 56,6 ), uma das quedas mais aceleradas do mundo - , a desigualdade de renda ainda encontra-se extremamente elevada, de modo que $1 \%$ da população brasileira mais rica detém o equivalente de renda total da mesma magnitude que a dos $50 \%$ mais pobres ${ }^{38}$.

Verifica-se, assim, que o Brasil não é um país pobre, mas um país injusto e desigual, com uma elevada concentração de renda, além de iniqüidades de inclusão econômica e social ${ }^{32}$. Esta desigualdade no Brasil, e em muitos países da América Latina, apresenta caráter histórico-estrutural — que se estende desde o período da colonização do continente ${ }^{39}$ - agravado pelo processo de globalização, que por sua vez ocasionou a dependência econômica dos países centrais, de onde surgem grupos populacionais com alto grau de discriminação, sem acesso ao trabalho e ao consumo, cujos direitos sociais e humanos foram regredindo ${ }^{36,40}$. Assim, percebe-se que tais direitos não estão enraizados nas relações sociais enquanto valores coletivos ${ }^{31,41}$.

"Desigualdade, pobreza e enfermidade constituem um típico movimento de retroalimentação" ${ }^{\prime 3}$. É bem conhecida a associação entre pobreza e outros elementos promotores de sofrimento e opressão, tais como (1) doença, (2) maiores índices de analfabetismo, (3) violência, (4) saneamento básico precário, (5) maior dificuldade de acesso a serviços de saúde em todos os níveis de atenção - os quais, quando utilizados, geralmente são de pior qualidade, albergando profissionais que possuem pior capacitação ou estão mais desmotivados (baixos salários, precarização do trabalho...) - (6) desemprego e (7) alimentação de baixa qualidade, somente para citar alguns. Todos estes fatores acabam por perpetuar tal ciclo e a condição de exclusão social de muitas pessoas ${ }^{33}$. As investigações em saúde demonstram que os piores índices de saúde encontram- 
se entre os grupos populacionais mais vulneráveis localizados na base da pirâmide social ${ }^{42}$.

Dados do Ministério da Saúde (2006) ${ }^{43}$ apontam para uma realidade de desigualdade em saúde - regional, étnica, de gênero e econômica. Por exemplo, o Nordeste é a região com menor expectativa de vida, cinco anos a menos do que na região Sul. A diferença de IDH entre negros e brancos chega a ser $16 \%$, sendo a educação a dimensão responsável pela maior diferença - a população negra possui menor escolaridade. Em 2005, 5\% da população com 15 anos ou mais dos estados de São Paulo, Rio Grande do Sul e Rio de Janeiro era analfabeta funcional. No Nordeste e Norte as proporções são ainda maiores, chegando a 30\% no estado de Alagoas. Além disso, as maiores taxas de analfabetismo concentram-se nos pequenos municípios (até 100 mil habitantes) ${ }^{43}$.

A população de etnia negra apresentou maior risco de morte por (1) doenças infecciosas e parasitárias, (2) condições relacionadas à gravidez, ao parto e ao puerpério, (3) causas externas e (4) causas mal-definidas. ${ }^{43} \mathrm{O}$ acesso a sete ou mais consultas pré-natais, em 2004, esteve relacionada a uma maior escolaridade materna, a boas condições socioeconômicas do município, a mães de cor branca, casadas e maiores de 19 anos. Assim, grupos socialmente mais vulneráveis foram os que receberam menor atenção pré-natal neste período ${ }^{43}$.

Em relação à mortalidade infantil, houve uma redução importante nas suas taxas em todas as regiões. Contudo, as condições de adoecimento e morte atingem maior número de crianças entre grupos sociais desfavorecidos. As maiores taxas puderam ser observadas entre os indígenas, sendo que a desnutrição foi a causa de $12 \%$ dos óbitos de crianças menores de um ano nessa população. ${ }^{43}$

A análise dos fatores associados a ser mãe antes dos 14 anos sugere que maior freqüência foi observada em meninas negras, residentes em municípios com até 100 mil habitantes e com alto índice de pobreza, em especial os localizados nas Regiões Norte e Centro-Oeste. Pode-se supor que as meninas residentes em municípios com essas características têm menor oferta de suporte social, de recursos educacionais e de saúde disponíveis para lidarem com o início de sua vida sexual. Também é possível que para muitas meninas se tornar mãe seja a conseqüência de situações de violência doméstica. ${ }^{43,39}$

Percebe-se, com efeito que as desigualdades manifestamse no espaço geográfico do país, expondo a história social, econômica e cultural de cada região, estado ou município. Nos grupos sociais mais vulneráveis (população rural, negros e índios), as desigualdades refletem a exclusão histórica desses grupos, existente até hoje ${ }^{43}$. Para o enfrentamento dessas condições adversas faz-se necessária a identificação e definição não só das necessidades e demandas em saúde, mas também das condições institucionais para viabilização das ações e dos caminhos a serem percorridos ${ }^{9}$ - o que inclui a formação adequada dos profissionais de saúde para atuar no SUS e nos seus diferentes níveis - especialmente na atenção básica de modo a torná-los capazes de enfrentar os problemas resultantes da pobreza e da desigualdade social tão presentes no cotidiano brasileiro.

\section{UMA RESPOSTA POSSÍVEL: REPENSANDO A FORMAÇÃO DOS PROFISSIONAIS DE SAÚDE À LUZ DOS PRINCÍPIOS DO SUS}

Os seres humanos são seres "inconclusos", cujas consciências se formam no âmbito de uma tríplice dialética, constituída, segundo Hegel, em torno de três elementos básicos: (1) as relações morais — família e vida social —, (2) a linguagem - processos de simbolização - e (3) o trabalho. ${ }^{44}$ No primeiro e no último âmbito - este, o trabalho, valorizado, sobremaneira, por Marx - se inscrevem as relações do homem com os outros homens e com a natureza. ${ }^{44}$ Com efeito, nos processos sociais e de trabalho se dão encontros de subjetividades, os quais têm grande preeminência nos modos de agir e de ser; tal síntese complexa também determina, de um modo ou de outro, as concepções e práticas em saúde. ${ }^{15,45,46}$ No entanto, para que esse espaço de subjetividades produza saberes e ações que levem em consideração a totalidade da relação profissional-usuário, é necessário que haja, tanto por parte da população quanto dos profissionais, o exercício da cidadania.

Sem embargo, há uma miríade de complicadores nesta equação. De fato, como questiona Bydlowski e colaboradores ${ }^{47}$ como falar em cidadania quando grande parte da população sobrevive em situação de extrema desigualdade social, sendo tratada como objeto de intervenções meramente assistencialistas? E como efetivá-la quando, dentro do atual modelo médico-hegemônico, perpetuam-se entraves à democracia e à participação da população?

A legislação brasileira considera a cidadania enquanto direito; entretanto, há um enorme abismo entre a letra da lei e seu cumprimento. ${ }^{11,48}$ De fato, algumas respostas podem ser traçadas a partir dos princípios e diretrizes operacionais do SUS, conforme estabelecido na Constituição Federal de 1988 e nas Leis Orgânicas da Saúde. Outras são advindas de conceitos como Promoção da Saúde, a qual insere em seu domínio o empoderamento - ampliação das possibilidades de controle, por um sujeito ou uma população, dos aspectos significativos relacionados à sua própria existência - e a 
libertação dos indivíduos e coletividades, bem como práticas pedagógicas que se baseiam na reflexão crítica dos sujeitos ${ }^{49,50}$.

Assim, resgatar os princípios do SUS - em uma perspectiva mais ampla de desigualdades sociais em saúde faz-se extremamente necessário, uma vez que os profissionais de saúde devem estar orientados para uma apreensão e ação voltados para o enfrentamento dessa realidade. Desta forma, a consolidação do SUS requer a renovação permanente de iniciativas que visem resgatar, assegurar e implementar os seus princípios. ${ }^{9,11}$

Por universalização do acesso aos serviços de saúde entende-se a ampliação do direito, em termos de cidadania, para toda a população, independente da situação ocupacional dos beneficiários, buscando a inclusão de todos os segmentos da sociedade no atendimento público. ${ }^{11}$

A eqüidade - conceito que pode ser recuperado de Aristóteles ${ }^{51}$, åđéåßêåéá, como o demarcado no Livro V da Ética a Nicômaco - deve se conformar em "ferramenta operacional de uma ética prática" que norteie as decisões e ações no campo da saúde em direção à garantia da efetivação do direito universal à saúde ${ }^{9}$. Ela está relacionada à capacidade de reconhecimento das diferenças e singularidades do outro e oferecimento de ações de saúde pertinentes a estas necessidades - ou seja, tratar desigualmente os desiguais para que se alcance, neste movimento, a justiça. O sentido da necessidade que orienta a eqüidade deve ser, preferencialmente, vocalizado pelos grupos ou pessoas às quais lhes falta. . $^{9} 37$

Costa e Lionço ${ }^{9}$ também alertam para o risco de se discutir a questão da eqüidade de forma superficial. É preciso "iluminar mais o cenário do cotidiano das pessoas e coletividades, buscando escutar e reconhecer as situações de iniqüidades" Estes mesmos autores ainda sugerem que se vá além da condição socioeconômica vulnerável, permitindo a escuta e a identificação da existência de situações de exclusão, relacionadas às diferentes condições, não apenas aquelas injustiças decorrentes de classe social. Deve-se levar em consideração a questão cultural, a territorialidade, a etnia, o gênero, a orientação sexual, a subjetividade e os demais aspectos de pessoas ou grupos em situação de exclusão de bens e serviços públicos.

Desta feita, os profissionais de saúde devem estar atentos para a realidade, buscando perceber as carências da população sob seu cuidado. Devem ainda, procurar conhecer as características demográficas, epidemiológicas, culturais, socioeconômicas, políticas, enfim, adentrar na comunidade. Só se cuida adequadamente daquilo que se conhece, do contrário, as ações não passam de esquemas aprendidos na academia e reproduzidos de modo completamente acrítico e desvinculado das necessidades das pessoas. Este conhecer também faz parte de dois outros princípios do SUS, a regionalização e hierarquização, os quais fazem referência ainda à importância da atenção primária como porta de entrada do sistema de saúde e da necessária comunicação que deve existir tanto entre os três níveis de atenção à saúde, quanto entre as três esferas do governo ${ }^{11,12}$.

Aqui cabe ressaltar os três pilares básicos da Vigilância da Saúde propostos por Mendes ${ }^{12}$, a saber: território, problemas de saúde intersetorialidade. $\mathrm{O}$ território vem resgatar a idéia de território-processo, território econômico, político, cultural e sanitário que deve ser conhecido, juntamente com os principais problemas de saúde, entendidos como a representação social de necessidades sanitárias, derivadas de condições de vida e formuladas por determinado ator social, com base em uma percepção de uma discrepância entre a realidade e uma norma instituída. Quanto à intersetorialidade, nesta propõe-se uma visão global, envolvendo diferentes setores que devem se comunicar, complementando suas ações. Assim, "a prática da vigilância da saúde parte do reconhecimento de um território para, nele, identificar, descrever e explicar os problemas aí contidos, definindo seus nós críticos e atuando, sobre eles, mediante um conjunto articulado de operações, organizadas intersetorialmente"12. Em um contexto de crescentes desigualdades sociais, estes pilares devem ser observados e aplicados de forma a reduzir as iniqüidades em saúde.

A integralidade, um outro princípio do SUS, propõe que haja uma comunicação eficiente entre os níveis de atenção, de forma a cuidar do indivíduo como um todo, isto é, de um sujeito inserido dentro de um contexto socioeconômico e cultural, na medida em que se reconhece que a saúde possui um conceito mais amplo do que apenas ausência de doença. Neste processo, um sério problema diz respeito à crescente especialização médica, que embora necessária não deve reduzir a saúde ao seu aspecto negativo — inexistência de condições mórbidas - desvinculando-a do seu contexto ${ }^{12,47,52}$.

Em relação à participação social, o profissional deve contribuir para a descoberta do indivíduo como sujeito autônomo - ou seja, desenvolvimento do empoderamento/libertação permitindo a auto-legislação, por meio do conhecimento, da intervenção nos determinantes de sua própria saúde e do seu bem-estar e, ainda, do bem-estar da comunidade no qual está inserido $8,13,46,53,54$. Costa e Lionço ${ }^{9}$ ressaltam a importância do fortalecimento do poder de vocalização dos grupos socais protagonistas da condição de exclusão. Assim, o sujeito deixa de ser mero expectador da sua realidade e passa a ser um ator social, um cidadão de direitos e deveres. 
Para que tal exercício seja efetivado, é necessário que seja rompida a equivocada invencibilidade da assistência médica, uma vez que "reconhecer as limitações do próprio saber significa admitir e validar outro saber (...) na identificação mais ampla dos problemas de saúde e na compreensão dos contextos de vida e dos recursos mobilizados pela população diante das carências, do sofrimento e da enfermidade". 55 Ressalta-se que a inclusão da "arte da alteridade", isto é, o deslocamento do "eu" em direção ao "outro", na formação em saúde é caminho para se alcançar a integralidade da atenção e, por conseguinte, a superação das práticas tradicionais em saúde. 8,56

Por fim, a descentralização das ações e serviços de saúde, que se refere à transferência do "lócus" das decisões, antes centralizadas em nível federal e/ou estadual, para os municípios, ${ }^{11}$ conferindo-lhes maior autonomia quanto à gestão de recursos - administrativos, financeiros e humanos - em saúde, para decidir e atuar conforme a realidade local, algo particularmente importante no Brasil, país extenso e que guarda grandes desigualdades regionais. Assim, os profissionais devem buscar delimitar seu papel, seu lugar e espaço no "território-processo".

Estes princípios, fixados pelos profissionais de saúde, precisam ser "apropriados da inteligência do seu conteúdo", orientando a ação e direcionando o olhar para a realidade, de forma a proporcionar o encontro entre teoria e prática. ${ }^{46,57}$

Assim, o processo de formação de recursos humanos em saúde deve ter como pilares fundamentais: (1) o pensamento crítico e produtivo, (2) o ensino em consonância com o serviço, (3) a conscientização do aluno frente à realidade da população, (4) a autonomia individual e coletiva, e (5) o aprendizado baseado nos problemas da população assistida, de modo que o profissional atue como sujeito transformador da realidade. ${ }^{8,53,58,59}$ Com efeito, o papel das instituições de nível superior deve ultrapassar os limites até então considerados como oficiais - mera reprodução intramuros de saberes - permitindo, outrossim, a composição entre erudição e criatividade, tão necessária à resolução dos problemas da coletividade.

De toda forma, vale ressaltar, ainda, que a educação em saúde deve ser voltada para as necessidades e demandas da comunidade, possibilitando um exercício da prática profissional que promova a autonomia, a cidadania, a participação social, a satisfação do usuário e a resolução de problemas através da produção de vínculo e acolhimento entre profissionais e usuários do serviço $3,8,13,48,53,57,60,61$.
Extrapolando o modo "freireano"para a práxis em saúde, o respeito à autonomia e à dignidade de cada indivíduo é de suma importância para o estabelecimento do acolhimento e vínculo, além de estimular o empoderamento/libertação e a participação social ${ }^{62-65}$. Este respeito só existirá quando os atores envolvidos - no caso o profissional de saúde e o usuário do serviço - mantiverem uma relação dialética na qual a criticidade, a humildade, a generosidade, a alteridade, a compaixão, o comprometimento, a tomada consciente de decisões, a escuta e o diálogo se tornem parte da realidade. ${ }^{46,53}$

\section{CONSIDERAÇÕES FINAIS}

Um dos capitais aspectos da formação do homem, especialmente no âmbito ético-político, é o reconhecimento de que o outro possui sonhos, medos, crenças, desejos e frustrações, os quais, quando matizados por uma realidade de injustiça, desigualdade e pobreza, tornam-se propícios à emergência do sofrimento e da desesperança. De fato, é o pai desempregado... O filho que chora por comida... A mãe doente sem condições de um tratamento adequado... Os laços familiares cada vez mais desgastados... A violência diária... O medo da morte... Enfim, diferentes situações iníquas, para as quais os profissionais devem se preparar, tendo sempre em vista o respeito à liberdade do outro.

Os desafios, neste contexto, são inúmeros, cabendo comentar a (1) premência de se aliar o conhecimento técnicocientífico às narrativas dos indivíduos aos quais se dirigirá o cuidado e (2) a necessidade de se inscrever na realidade do outro, auxiliando na transformação daquilo que, identificado por ambos com um problema, precisará ser mudado. É importante que se exercite, diuturnamente, a "arte da alteridade", ou seja, o abrir-se ao outro, às suas diferentes representações sociais e formas de enfrentamento das adversidades do cotidiano, movimento capaz de permitir a construção de novos significados.

Como formar este profissional? — eis a questão. Neste sentido, cabe a revisão radical do papel das instituições de ensino - o aparelho formador - na educação dos seus estudantes. A adoção de um posicionamento encastelado, não permissivo ao diálogo dentro e fora dos muros institucionais - por exemplo, com os órgãos responsáveis pela prestação de serviço, com a sociedade civil organizada, dentre outros é um grave contra-senso, ao se ter em vista a perspectiva de devolver à sociedade um profissional que seja capaz, precisamente, de dialogar. 


\section{REFERÊNCIAS}

1. Noronha AB, Sophia D, Machado K. Formação profissional em saúde. Radis 2002; 3:11-7.

2. Pereira ALF. As tendências pedagógicas e a prática educativa na ciência da saúde. Cad Saude Publica 2003; 19(5): 1527-34.

3. Amâncio Filho A. Dilemas e desafios de formação profissional em saúde. Interface 2004; 15(8): 375-80.

4. Jaeger W. Paidéia: a formação do Homem grego. São Paulo: Martins Fontes; 1995.

5. Costa CRBSF, Siqueira-Batista R. As teorias do desenvolvimento moral e o ensino médico: uma reflexão pedagógica centrada na autonomia do educando. Rev Bras Edu Med 2004; 28(3):242-50.

6. Silva JA, Ypiranga L, Seixas JC, Jatene AD. Tendências da graduação na área da saúde no Brasil. Educ Med Salud 1994; 28(2):286-300.

7. Bourdieu P. Razões Práticas: sobre a teoria da ação. Campinas: Papirus; 1996.

8. Ceccim RB, Feuerwerker LCM. O quadrilátero da formação para a área da saúde: ensino, gestão, atenção e controle social. Physis 2004; 14(1):41-65.

9. Costa AM, Lionço T. Democracia e Gestão Participativa: uma estratégia para a equidade em saúde? Saúde e Sociedade 2006; 15(2):47-55.

10. Menicucci TMG. Implementação da reforma sanitária: a formação de uma política. Saúde e Sociedade 2006; 15(2):72-87.

11. Cotta RMM, Mendes FF, Muniz JN. Descentralização das Políticas Públicas de Saúde. Do Imaginário ao Real. Viçosa: Ed. UFV; 1998.

12. Mendes EV.Uma agenda para a saúde. São Paulo: Hucitec; 1998.

13. Ceccim RB, Bilibio LFS. Articulação com o Segmento Estudantil da Área da Saúde: uma Estratégia de Inovação na Formação Recursos Humanos para o SUS. In: Brasil, Ministério da Saúde. VER-SUS Brasil: Caderno de Textos. Brasília: Ministério da Saúde; 2004. p.9-31.

14. Silva Santos S. A integração do ciclo básico com o profissional, no curso de graduação em medicina: uma resistência exemplar. Rio de Janeiro: Papel \& Virtual; 2005.

15. Feuerwerker LCM. Estratégias para a mudança da formação dos profissionais de saúde. Caderno CE 2001; 4(2):11-23.

16. Brasil Ministério da Saúde. Secretaria de Gestão do Trabalho e da Educação na Saúde. Departamento de Gestão da Educação na Saúde. Ver-SUS Brasil: cadernos de textos.
Brasília: Ministério da Saúde; 2004. (Série B. Textos Básicos de Saúde). p. 37-61

17. Schaedler LI. Sistema Único de Saúde como Rede em Prática Pedagógica. In: Brasil, Ministério da Saúde. VER-SUS Brasil: Caderno de Textos. Brasília: Ministério da Saúde; 2004. p.85-91.

18. Amorim STSP, Moreira H, Carraro TE. A formação de pediatras e nutricionistas: a dimensão humana. Rev Nut Campinas 2001; 14(2):111-118.

19. Vilela EM, Mendes IJM. Interdisciplinaridade e saúde: estudo bibliográfico. Rev Lat Am Enfermagem 2003; 11(4):525-531.

20. Programa das Nações Unidas para o Desenvolvimento. Relatório de Desenvolvimento Humano 2006: a água para lá da escassez: poder, pobreza e a crise mundial da água.

21. Programa das Nações Unidas para o Desenvolvimento. Relatório de Desenvolvimento Humano2002: aprofundar a democracia num mundo fragmentado.

22. Programa das Nações Unidas para o Desenvolvimento. Relatório de Desenvolvimento Humano 2000: Direitos humanos e desenvolvimento humano: pela liberdade e solidariedade.

23. Programa das Nações Unidas para o Desenvolvimento. Relatório de Desenvolvimento Humano 1999. Globalização com uma face humana.

24. Programa das Nações Unidas para o Desenvolvimento. Relatório de Desenvolvimento Humano: Racismo, pobreza e violência.

25. Programa das Nações Unidas para o Desenvolvimento. Relatório de Desenvolvimento Humano 2004: Liberdade Cultural num Mundo Diversificado

26. Programa das Nações Unidas para o Desenvolvimento. Relatório de Desenvolvimento Humano 1997: Desenvolvimento Humano para erradicar a pobreza.

27. Nações Unidas. Declaração do Milênio. [on line]. Nova Iorque: Cimeira do Milênio; 2000 [capturado 25 abr. 2006] Disponível em: http://www.pnud.org.br/odm/ index.php?lay=odmi\&id=odmi.

28. Universidade Federal do Rio Grande do Sul, Pontifícia Universidade Católica de Minas Gerais, Programa das Nações Unidas para o Desenvolvimento orgs. Pobreza e fome: objetivo 1: erradicar a extrema pobreza e a fome. [on line]. Belo Horizonte: PUC Minas; 2004. [capturado 25 abr. 2006] Disponível em: http://www.pnud.org.br/ estudos/index.php (Coleção de estudos temáticos sobre os objetivos de desenvolvimento do milênio da rede de laboratórios para acompanhamento dos objetivos de desenvolvimento do milênio). 
29. Declaração do Rio. [on line]. Rio de Janeiro; 2006 [capturado 25 abr. 2006] Disponível em: http://www.abrasco.org.br/ publicacoes/arquivos/20060905175107.pdf (Documento resultante dos debates realizados no $8^{\circ}$ Congresso Brasileiro de Saúde Coletiva e 11º Congresso Mundial de Saúde Pública ocorrido no Rio de Janeiro 21-25 de agosto de 2006)

30. Brasil. Ministério da Saúde. Decreto de 13 de março de 2006. Brasília: Ministério da Saúde; 2006.

31. Magalhães R. Enfrentando a pobreza, reconstruindo vínculos sociais: as lições da Ação da Cidadania contra a Fome, a Miséria e pela Vida. Cad Saude Publica 2002; 18 Supl:121-37.

32. Novara E. Promover os talentos para reduzir a pobreza. Estudos Avançados 2003; 17(48):101-23.

33. Siqueira-Batista R, Schramm FR. A saúde entre a iniqüidade e a justiça: contribuições da igualdade complexa de Amartya Sen. Ciên Saúde Col 2005; 10(1):129-42.

34. Fukuda-Parr S. The Human Poverty Index: a multidimensional measure. Journal Poverty in Focus [on line] 2006 [Capturado 21 abr. 2007] Disponível em: http: / / w w w . und p - povertycentre.org / p u b / IPCPoverty_in_Focus009.pdf.

35. Edward P. The Ethical Poverty Line: a moral definition of absolute poverty. Journal Poverty in Focus [on line] 2006 [Capturado 21 abr. 2007] Disponível em: http:// w w w. und p - povertycentre.org / p u b / IPCPoverty_in_Focus009.pdf.

36. Wanderley MB. Sistema de Informação em gestão social. Estudos Avançados 2006; 20(56):149-58.

37. Barata RB. Desigualdades sociais e saúde. In: Gastão WSC et al. Tratado de Saúde Coletiva. São Paulo: Hucitec; Rio de Janeiro: Ed. Fiocruz; 2006.

38. Barros RP, Carvalho M, Franco S, Mendonça R. A queda recente da desigualdade de renda no Brasil. Instituto de Pesquisa Econômica Aplicada. Rio de Janeiro; 2007. (Texto para discussão n⿳0 1258).

39. Siqueira-Batista R. Miséria. 3. ed. Rio de Janeiro: Kroart; 2007.

40. Marsiglia RMG, Silveira C, Carneiro Jr N. Políticas sociais: desigualdade, universalidade e focalização na saúde no Brasil. Saúde e Sociedade 2005; 14(2):69-76.

41. Prata PR. Desenvolvimento econômico, desigualdade e saúde. Cad Saude Publica 1994; 10(3):387-91.

42. Viana A, Fausto MCR, Lima LD. Política de saúde e equidade. São Paulo em Perspectiva 2003; 7(1):58-68.

43. Brasil. Ministério da Saúde. Secretaria de Vigilância em Saúde. Departamento de Análise de Situação em Saúde.
Saúde Brasil 2006: uma análise da situação de saúde no Brasil. Brasília; 2006.

44. Hegel GWF. A fenomenologia do espírito. Petrópolis: Vozes; 1992.

45. L'Abbate S. Educação e serviços de saúde: avaliando a capacitação dos profissionais. Cad. Saude Publica 1999; 15(suppl2).p.3

46. Freire P. Pedagogia da autonomia: saberes necessários à prática educativa. 35. ed. São Paulo: Paz e Terra; 2007.

47. Bydlowski CR, Wetphal MF, Pereira IMT. Promoção da saúde. Porque sim e porque ainda não! Saúde e Sociedade 2004; 22(13):14-24.

48. Machado MFAS, Monteiro EMLM, Queiroz DT, Vieira NFC, Barroso MGT. Integralidade, formação de saúde, educação em saúde e as propostas do SUS: uma revisão conceitual. Cien Saude Colet 2007; 12(2):335-42.

49. Organização Mundial da Saúde. Carta de Ottawa. Primeira Conferência Internacional sobre Promoção da Saúde; 1986.

50. Sícoli JL, Nascimento PR. Promoção de saúde: concepções, princípios e operacionalização. Interface 2003; 7(12):101-22.

51. Aristóteles. Ética a Nicômaco. Brasília: Ed. Universidade de Brasília; 1985.

52. Barros JAC. Pensando o processo saúde doença: A que responde o modelo biomédico? Saúde e Sociedade 2002; 11(1): 67-84.

53. L'Abbate S. Educação em saúde: uma nova abordagem. Cad Saude Publica 1994; 10(4):481-90.

54. Bosi MLM, Affonso KC. Cidadania, participação popular e saúde: com a palavra, os usuários da Rede Pública de Serviços. Cad Saude Publica 1998; 14(2):355-65.

55. Stots EN, Araújo JWG. Promoção da saúde e cultura política: a reconstrução do consenso. Saúde e Sociedade 2004; 13(2):5-19.

56. Abbagnano, N. Dicionário de filosofia. 4. ed. São Paulo: Martins Fontes; 2003.

57. Cotta RMM, Pereira RJ, Maia TM, Marques ES, Franceschini SCC. Aprehensión y conocimiento de las directrices del Sistema Único de salud (SUS): un reto en la consolidación de la política de salud brasileña. Agathos: Atención Sociosanitaria y Bienestar 2004, 4(3):16-23.

58. Struchiner M, Roschke MA, Ricciardi RMV. Formação permanente, flexível e a distância pela Internet: Curso de Gestão Descentralizada de Recursos Humanos em Saúde. Rev Panam Salud Publica 2002; 11(3):158-65. 
59. Secco GL, Pereira MLT. Formadores em odontologia: profissionalização docente e desafios político-estruturais. Cien Saude Colet 2004; 9(1):113-20.

60. Brasil. Ministério da Saúde. Nota técnica sobre a iniciativa do Ministério da Saúde para estimular a mudança na graduação das profissões de saúde, conforme política de educação para o SUS. [on line]. Brasília, Brasil [capturado 10 set. 2004]. Disponível em: http://www.ccs.ufpb.br/ nesc/APRENDERSUS.doc.

61. Schimith MD, Lima MADS. Acolhimento e vínculo do Programa Saúde da Família. Cad Saude Publica 2004; 20(6):1487-94.

62. Sen A. Desenvolvimento como liberdade. São Paulo: Companhia das letras; 2000.

63. Sen A. Desigualdade Reexaminada. Rio de Janeiro: Ed. Record; 2001.

64. Freire P. Pedagogia do oprimido. 38. ed. São Paulo: Paz e Terra; 2004.
65. Garrafa V. A inclusão social no contexto da bioética. (Conferência apresentada no Seminário Mensal julho/2005 da ANVISA, em Brasília-DF e no painel "Bioética: inclusão e justiça social". VI Congresso Nacional da REDE UNIDA, Belo Horizonte: 2005).

\section{CONFLITO DE INTERESSE}

Declarou não haver.

\section{ENDEREÇO PARA CORRESPONDÊNCIA}

Profa. Rosângela Minardi Mitre Cotta

Universidade Federal de Viçosa - UFV

Departamento de Nutrição e Saúde

Avenida P.H, Rolfs s/n - Campus Universitário CEP 36.570.000 - Viçosa - MG - Brasil.

Tel.: 5531 3899-1278 Fax: 55318992541

E-mail: rmmitre@ufv.br 